\title{
Is repair preferable to replacement for ischemic mitral regurgitation?
}

\author{
A. Marc Gillinov, MDa \\ Per Nils Wierup, $\mathrm{MD}^{\mathrm{a} *}$ \\ Eugene $\mathrm{H}$. Blackstone, $\mathrm{MD}^{\mathrm{a}, \mathrm{b}}$ \\ Ehab S. Bishay, MDa \\ Delos M. Cosgrove, MDa \\ Jennifer White, $\mathrm{MS}^{\mathrm{b}}$ \\ Bruce W. Lytle, MDa \\ Patrick M. McCarthy, MD
}

See related editorial on page 1059
From the Department of Thoracic and Cardiovascular Surgery ${ }^{\mathrm{a}}$ and the Department of Biostatistics and Epidemiology, ${ }^{b}$ The Cleveland Clinic Foundation, Cleveland, Ohio.

Read at the Eightieth Annual Meeting of The American Association for Thoracic Surgery, Toronto, Ontario, Canada, April 30-May 3, 2000.

Received for publication May 3, 2000; revisions requested Sept 5, 2000; revisions received March 14, 2001; accepted for publication April 11, 2001.

Address for reprints: A. Marc Gillinov, MD, The Cleveland Clinic Foundation, 9500 Euclid Ave, Desk F25, Cleveland, OH 44195 (E-mail: gillinom@ccf.org).

*Currently at Department of Cardiothoracic Surgery, Aarhus University Hospital, Aarhus, Denmark.

J Thorac Cardiovasc Surg 2001;122:1125-41 Copyright (C) 2001 by The American Association for Thoracic Surgery

0022-5223/2001 $\$ 35.00+0 \quad \mathbf{1 2 / 6 / 1 1 6 5 5 7}$

doi:10.1067/mtc.2001.116557
Objective: This study was undertaken to compare mitral valve repair and replacement as treatments for ischemic mitral regurgitation.

Methods: From 1985 through 1997, a total of 482 patients with ischemic mitral regurgitation underwent either valve repair $(n=397)$ or valve replacement $(n=85)$. Patients more likely $(P \leq .01)$ to undergo repair had functional mitral regurgitation or coronary revascularization with an internal thoracic artery graft; those more likely to receive valve replacement were in higher New York Heart Association functional classes or underwent emergency operations. These factors were used for multivariable propensity matching. Risk factors for early and late death were identified by multivariable, multiphase hazard function analysis.

Results: Within the propensity-matched better-risk group, survivals after valve replacement were $81 \%, 56 \%$, and $36 \%$ at 30 days, 1 year, and 5 years, but survivals after repair were $94 \%, 82 \%$, and $58 \%$ at these intervals $(P=.08)$. In contrast, within the poor-risk group, survivals after repair and replacement were similar $(P=.4)$. Risk factors $(P \leq$ $.01)$ included older age, higher functional class, greater wall motion abnormality, and renal dysfunction. Approximately $70 \%$ of patients were predicted to benefit from repair; the benefit lessened or was negated if an internal thoracic artery graft was not used, if a lateral wall motion abnormality was present, or if the mitral regurgitation jet pattern was complex. Freedom from repair failure at 5 years was $91 \%$.

Conclusion: Late survival is poor after surgery for ischemic mitral regurgitation. Most patients with ischemic mitral regurgitation benefit from mitral valve repair. In the most complex, high-risk settings, survivals after repair and replacement are similar.

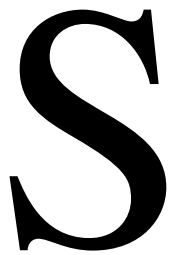

urgical treatment of ischemic mitral regurgitation is associated with a high operative mortality rate and poor long-term survival. Choosing the most appropriate surgical treatment to maximize survival for these patients is made difficult by inconsistent classification schemes for the entity, a paucity of long-term data to compare alternatives, and an absence of randomized trials of valve repair versus valve replacement. In fact, such trials are unlikely ever to be undertaken. The purposes of this study were therefore to develop a simple and clinically useful echocardiographic classification scheme, to determine which patients were more likely to receive valve repair rather than replacement at this center, to determine whether survival was better after mitral valve repair or replacement, to discover which patients benefit from valve repair and which from replacement, and to quantify the durability of valve repair.

The Journal of Thoracic and Cardiovascular Surgery • Volume 122, Number 61125 


\section{TABLE 1. Patient characteristics}

\begin{tabular}{|c|c|c|c|c|c|c|c|}
\hline & \multicolumn{2}{|c|}{$\begin{array}{c}\text { Total } \\
(n=482)\end{array}$} & \multicolumn{2}{|c|}{$\begin{array}{l}\text { Mitral repair } \\
(\mathrm{n}=397)\end{array}$} & \multicolumn{2}{|c|}{$\begin{array}{l}\text { Mitral replacement } \\
(\mathrm{n}=85)\end{array}$} & \multirow[b]{2}{*}{$P$} \\
\hline & No. & $\%$ & No. & $\%$ & No. & $\%$ & \\
\hline \multicolumn{8}{|l|}{ Demographic characteristics } \\
\hline Age (y) & & & & & & & $.4^{*}$ \\
\hline$<50$ & 26 & 5 & 23 & 6 & 3 & 4 & \\
\hline$\geq 50-60$ & 83 & 17 & 72 & 18 & 11 & 13 & \\
\hline$\geq 60-70$ & 187 & 39 & 149 & 38 & 38 & 45 & \\
\hline$\geq 70$ & 186 & 39 & 153 & 39 & 33 & 39 & \\
\hline Male & 261 & 54 & 221 & 56 & 40 & 47 & .15 \\
\hline \multicolumn{8}{|l|}{ Cardiac comorbidity } \\
\hline NYHA functional class $\dagger$ & & & & & & & $<.0001^{*}$ \\
\hline I & 1 & 0.2 & 1 & 0.2 & 0 & 0 & \\
\hline ॥ & 155 & 32 & 143 & 37 & 12 & 14 & \\
\hline III & 143 & 30 & 121 & 31 & 22 & 26 & \\
\hline IV & 175 & 36 & 124 & 32 & 51 & 60 & \\
\hline Emergency surgery & 37 & 8 & 12 & 3 & 25 & 29 & $<.0001$ \\
\hline Preoperative intra-aortic balloon pump & 58 & 12 & 30 & 8 & 28 & 33 & $<.0001$ \\
\hline Left main coronary artery disease $(\geq 50 \%)$ & 100 & 21 & 88 & 22 & 12 & 14 & .1 \\
\hline $\begin{array}{l}\text { Left anterior descending coronary } \\
\text { artery disease }(\geq 50 \%)\end{array}$ & 406 & 84 & 348 & 88 & 58 & 68 & $<.0001$ \\
\hline $\begin{array}{l}\text { Lateral circumflex coronary } \\
\text { artery disease }(\geq 50 \%)\end{array}$ & 384 & 80 & 312 & 79 & 72 & 85 & .2 \\
\hline Right coronary artery disease $(\geq 50 \%)$ & 427 & 89 & 359 & 90 & 68 & 80 & .006 \\
\hline Coronary system disease $(\geq 50 \%)$ & & & & & & & .002 \\
\hline 0 & 3 & 0.6 & 2 & 0.5 & 1 & 1 & \\
\hline 1 & 49 & 10 & 36 & 9 & 13 & 15 & \\
\hline 2 & 122 & 25 & 94 & 24 & 28 & 33 & \\
\hline 3 & 308 & 64 & 265 & 67 & 43 & 50 & \\
\hline \multicolumn{8}{|l|}{ Myocardial infarctionł } \\
\hline Within $14 \mathrm{~d}$ of surgery & 95 & 20 & 62 & 16 & 33 & 39 & $<.0001$ \\
\hline$>14 \mathrm{~d}$ before surgery & 382 & 80 & 332 & 84 & 50 & 60 & $<.0001$ \\
\hline Left ventricular dysfunction & & & & & & & $.0003 \S$ \\
\hline None & 56 & 12 & 37 & 9 & 19 & 22 & \\
\hline Mild & 77 & 16 & 61 & 15 & 16 & 19 & \\
\hline Moderate & 180 & 32 & 150 & 38 & 30 & 35 & \\
\hline Severe & 169 & 35 & 149 & 38 & 20 & 24 & \\
\hline
\end{tabular}

* Logistic test for trend.

tCould not be determined for 8 patients undergoing mitral valve repair.

†Timing of myocardial infarction could not be determined for 5 patients. §Logistic test for trend.

Data unavailable for 47 repair group and 11 replacement group patients.

IData missing for 6 repair group and 26 replacement group patients.

**Missing values for 73 repair group and 11 replacement group patients. t†Logistic test for trend.

$\ddagger \ddagger$ Missing values for 11 repair group and 2 replacement group patients.

\section{Methods \\ Patients}

Study group. From 1985 through 1997, records of 482 consecutive patients undergoing either mitral valve repair $(n=397)$ or replacement $(n=85)$ for ischemic mitral regurgitation were found. The Cardiovascular Information Registry was used to discriminate nearly 2000 potential patients with this condition. Their clinical records were reviewed to determine whether their mitral regurgitation was indeed caused by ischemic heart disease and did not just coexist with it (see Definitions section). All patients had at least $2+$ (moderate) mitral regurgitation. The decision to perform mitral valve surgery was made by the operating surgeon and the cardiologist on the basis of clinical presentation and findings at cardiac catheterization and echocardiography. In general it has been our policy to perform mitral valve surgery for mitral regurgitation that is $3+$ or greater. Patients with any degree of mitral regurgitation who did not undergo a surgical procedure on the mitral valve were not included in this study. Patients who underwent concomitant aortic valve procedures were also excluded and are discussed in a separate report. Patients who underwent left ventricular restoration procedures (Batista procedure, Dor procedure) were also excluded and similarly are discussed in separate reports. 
TABLE 1. Patient characteristics-Cont'd

\begin{tabular}{|c|c|c|c|c|c|c|c|}
\hline & \multicolumn{2}{|c|}{$\begin{array}{c}\text { Total } \\
(n=482)\end{array}$} & \multicolumn{2}{|c|}{$\begin{array}{l}\text { Mitral repair } \\
(\mathrm{n}=397)\end{array}$} & \multicolumn{2}{|c|}{$\begin{array}{l}\text { Mitral replacement } \\
\quad(\mathrm{n}=85)\end{array}$} & \multirow[b]{2}{*}{$\boldsymbol{P}$} \\
\hline & No. & $\%$ & No. & $\%$ & No. & $\%$ & \\
\hline \multicolumn{8}{|l|}{ Wall motion abnormality\| } \\
\hline Anterior & 171 & 40 & 153 & 43 & 18 & 24 & .002 \\
\hline Septal & 163 & 42 & 146 & 42 & 17 & 23 & .003 \\
\hline Posterior & 262 & 63 & 221 & 63 & 41 & 55 & .2 \\
\hline Lateral & 186 & 44 & 155 & 44 & 31 & 42 & .08 \\
\hline Inferior & 303 & 73 & 257 & 73 & 46 & 67 & .05 \\
\hline Atrial fibrillation & 159 & 33 & 132 & 33 & 27 & 32 & .8 \\
\hline Previous cardiac surgery & 110 & 23 & 95 & 24 & 15 & 18 & .2 \\
\hline \multicolumn{8}{|l|}{ Noncardiac comorbidity } \\
\hline Hypertensionף & 290 & 64 & 238 & 64 & 52 & 66 & .8 \\
\hline Chronic obstructive pulmonary disease & 93 & 19 & 70 & 18 & 23 & 27 & .05 \\
\hline $\begin{array}{l}\text { Diabetes (treated with oral hypoglycemic } \\
\text { agents or insulin) }\end{array}$ & 131 & 27 & 105 & 28 & 26 & 32 & .5 \\
\hline Renal dysfunction & 43 & 9 & 32 & 8 & 11 & 13 & .15 \\
\hline Creatinine $(\mathrm{mg} / \mathrm{dL})^{* *}$ & & & & & & & $.02 t \dagger$ \\
\hline$<1.1$ & 111 & 28 & 99 & 31 & 12 & 16 & \\
\hline$\geq 1.1-1.3$ & 100 & 25 & 78 & 24 & 22 & 30 & \\
\hline$\geq 1.3-1.6$ & 99 & 25 & 78 & 24 & 21 & 28 & \\
\hline$\geq 1.6$ & 88 & 22 & 69 & 21 & 19 & 26 & \\
\hline Blood urea nitrogen $(\mathrm{mg} / \mathrm{dL}) \ddagger \ddagger$ & & & & & & & $.06^{* *}$ \\
\hline$<17$ & 111 & 24 & 97 & 25 & 14 & 17 & \\
\hline$\geq 17-23$ & 132 & 28 & 111 & 29 & 21 & 25 & \\
\hline$\geq 23-29$ & 108 & 23 & 89 & 23 & 19 & 23 & \\
\hline$\geq 29$ & 118 & 25 & 89 & 23 & 29 & 35 & \\
\hline
\end{tabular}

The mean age of patients undergoing mitral valve repair was 67 \pm 9.2 years, similar to that among those receiving mitral valve replacement $(67 \pm 8.7$ years, $P=.4)$. Patient characteristics overall and according to whether the patient underwent repair or mitral valve replacement are tabulated in Table 1.

Definitions. Ischemic mitral valve disease was classified from analysis of clinical information, operative reports, and echocardiograms. Mitral regurgitation was judged to be ischemic in origin when the valve leaflets and chordae were normal and the regurgitation was caused by the consequences of a myocardial infarction. Thus all patients in this study had at least one previous myocardial infarction. Twenty percent of these events were within 2 weeks of surgery. Ten patients with transient mitral regurgitation caused by intermittent ischemia were not included in this study, even though they underwent valve repair. Patients with ischemic heart disease but also clear evidence of degenerative, rheumatic, or infective mitral valve disease were also excluded. Patients with isolated ruptured chordae were considered to have degenerative mitral valve disease.

Ischemic mitral regurgitation was further subdivided into three mechanisms of regurgitation: (1) ruptured papillary muscle, (2) infarcted papillary muscle without rupture, and (3) functional regurgitation. Patients with elongated and infarcted but unruptured papillary muscles were classified as having infarcted papillary muscles. Patients with isolated functional mitral regurgitation had normal papillary muscles, chordae, and leaflets; however, the leaflets failed to coapt, and echocardiograms frequently demonstrated restricted leaflet motion. Thus patients with functional mitral regurgitation included those with Carpentier type I and IIIb leaflet motion. Mitral regurgitation was functional in $76 \%$ of the cases, papillary muscle infarction without rupture was present in $24 \%$, and papillary muscle rupture was present in $9 \%$ (Table 2). Components of both papillary muscle pathologic changes and functional regurgitation were present in $9 \%$ of the cases.

Echocardiograms. Echocardiograms for analysis of the regurgitant jet direction were available for 364 patients (76\%). Jet direction was recorded as anterior, posterior, central, or complex (Table 2). A complex jet was specified when there were multiple jets or the jet was eccentric (eg, posterolateral or anterolateral).

Regional wall motion abnormalities were documented with echocardiograms or ventriculograms from cardiac catheterization (Figure 1). Abnormalities were categorized as being anterior, septal, inferior, posterior, and lateral in location (Appendix I, Table 1; Figure 1).

Surgical details. The 482 operations were performed by 14 surgeons. Of these, 6 performed 32 or more operations, and each was considered a variable in the analysis. The remaining 8 surgeons, who performed 2 to 15 operations each, were grouped for analysis. The most common repair technique was mitral annuloplasty (98\%); this was the only repair technique in 314 cases (79\%; Table 3). Eighteen of 42 patients (43\%) with papillary muscle rupture underwent mitral valve repair, with papillary muscle reimplantation in 12 cases. Among the patients who received mitral valve replacement, 50 (59\%) received bioprostheses and 35 (41\%) received mechanical valves. Concomitant coronary artery bypass 
TABLE 2. Valve pathophysiology

\begin{tabular}{|c|c|c|c|c|c|c|c|}
\hline & \multicolumn{2}{|c|}{$\begin{array}{c}\text { Total } \\
\text { (n= 482) }\end{array}$} & \multicolumn{2}{|c|}{$\begin{array}{c}\text { Mitral repair } \\
(\mathrm{n}=397)\end{array}$} & \multicolumn{2}{|c|}{$\begin{array}{l}\text { Mitral replacement } \\
\qquad(\mathrm{n}=85)\end{array}$} & \multirow[b]{2}{*}{$\boldsymbol{P}$} \\
\hline & No. & $\%$ & No. & $\%$ & No. & $\%$ & \\
\hline \multicolumn{8}{|c|}{ Classification of ischemic mitral regurgitation } \\
\hline Functional & 365 & 76 & 327 & 82 & 38 & 45 & $<.0001$ \\
\hline Alone ${ }^{*}$ & 322 & 67 & 294 & 74 & 28 & 33 & $<.0001$ \\
\hline With infarcted papillary muscle & 43 & 9 & 33 & 8 & 10 & 12 & .3 \\
\hline Without rupture & 39 & 8 & 31 & 8 & 8 & 9 & \\
\hline With rupture & 4 & 0.8 & 2 & 0.5 & 2 & 2 & \\
\hline Infarcted papillary muscle & 160 & 33 & 103 & 26 & 57 & 67 & $<.0001$ \\
\hline Without rupture* & 117 & 24 & 84 & 21 & 33 & 39 & .0006 \\
\hline With rupture* & 43 & 9 & 19 & 5 & 24 & 28 & $<.0001$ \\
\hline \multicolumn{8}{|l|}{ Mitral regurgitation jet directiont } \\
\hline Central & 211 & 58 & 187 & 61 & 24 & 41 & .005 \\
\hline Anterior & 24 & 7 & 17 & 6 & 7 & 12 & .08 \\
\hline Posterior & 74 & 20 & 56 & 18 & 18 & 31 & .03 \\
\hline Complex & 55 & 15 & 46 & 15 & 9 & 16 & .9 \\
\hline \multicolumn{8}{|l|}{ Severity of mitral regurgitation } \\
\hline 2 & 23 & 5 & 22 & 6 & 1 & 1 & $<.0001$ \\
\hline 3 & 216 & 45 & 198 & 50 & 18 & 22 & \\
\hline 4 & 236 & 50 & 172 & 44 & 64 & 77 & \\
\hline
\end{tabular}

*These categories are mutually exclusive.

tData were unavailable for 91 repair group and 27 replacement group patients.

TABLE 3. Mitral valve repair techniques $(n=397)$

\begin{tabular}{lcc}
\hline Technique & No. & $\%$ \\
\hline Annuloplasty & 388 & 98 \\
Annuloplasty type & & \\
$\quad$ Carpentier-Edwards & 134 & 34 \\
Cosgrove-Edwards Annulo- & 140 & 35 \\
$\quad$ plasty System* & & \\
Bovine pericardial graft & 112 & 28 \\
$\quad$ Autologous pericardium & 2 & 0.5 \\
Annuloplasty size (mm)† & & \\
26 & 80 & 30 \\
28 & 73 & 28 \\
30 & 58 & 21 \\
32 & 43 & 16 \\
34 & 10 & 4 \\
36 & 4 & 1 \\
Leaflet resection & 17 & 4 \\
Papillary muscle shortening & 34 & 10 \\
Papillary muscle reimplantation & 12 & 3 \\
Chordal shortening & 27 & 7 \\
Chordal transfer & 9 & 2 \\
\hline
\end{tabular}

* In 1 case an Alfieri stitch was also used.

tIncludes only patients with Carpentier-Edwards or Cosgrove-Edwards annuloplasty $(n=274)$; data unavailable for 6 patients.

grafting was performed in 460 cases (95\%), 385 (97\%) in the repair group and $75(88 \%)$ in the replacement group $(P=.002)$. An internal thoracic artery (ITA) graft was used for 17 (20\%) of the patients who received mitral valve replacement and $185(47 \%)$ of the patients who underwent repair $(P<.0001)$. Twenty patients $(4 \%)$ underwent concomitant tricuspid valve repair.

Follow-up. Patients were followed up systematically at 2-year intervals with a mailed questionnaire, a telephone interview, or examination at The Cleveland Clinic Foundation. Follow-up extended reliably to 7 years, with 1296 patient-years of information available for analysis. Mean follow-up among survivors was $3.3 \pm 2.4$ years, with $50 \%$ followed up for more than 2 years, $25 \%$ for more than 4 years, and $10 \%$ for more than 6 years.

\section{Data Analysis}

Overview. The data analysis first addressed the question, "Were patients undergoing mitral valve repair similar to those undergoing replacement?" The answer to that question was no. Therefore a matched group of patients was assembled to answer a second question: "Is survival better after mitral valve repair than after replacement?" However, these patients represented only one end of the spectrum of ischemic mitral regurgitation (the most complex with the sickest patients). Multivariable analyses of mortality were therefore performed separately for repair and replacement groups. These analyses were then combined, including an analysis of interactions, to yield an overall equation for comparison of repair and replacement propensity-adjusted for selection factors in choice of procedure. We then asked, "Which patients benefit from which procedure?" Multivariable simulation was used to answer that question. Finally, we asked, "Is mitral valve repair durable?" We answered this question by analyzing repair failure. Details of the methodology are supplemented by material in Appendix II.

Were patients undergoing mitral valve repair similar to those undergoing replacement? To answer this question, multivariable logistic regression was used to identify factors associated with 


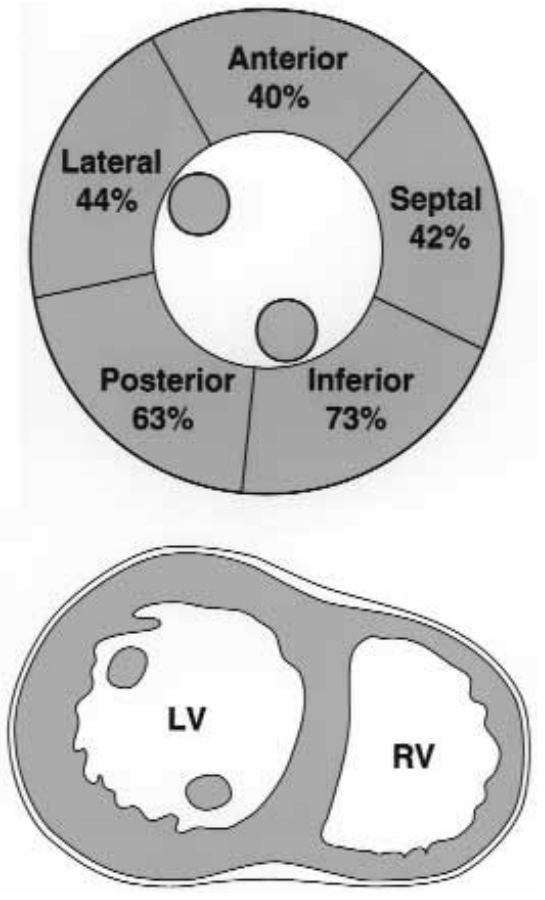

Figure 1. Sites of left ventricular wall motion abnormalities in patients with ischemic mitral regurgitation. Schematic representation of short-axis view of left ventricle corresponding to labeled figure below. Papillary muscles are denoted by circles.

valve repair rather than replacement. In this analysis demographic characteristics, symptoms and clinical status, left ventricular function, pathyphysiology of valve disease, cardiac comorbidity, noncardiac comorbidity, and concomitant coronary artery procedure variables were considered (Appendix III). Details of risk factor identification are given in Appendix II. After examining these patient factors we explored surgeon differences.

The latter parsimonious analysis was amplified into a propensity model by adding nonsignificant variables representing gender, body size (body mass index), preoperative use of an intra-aortic balloon pump, coronary system disease greater than $50 \%$, hypertension, treated diabetes, peripheral vascular disease, chronic obstructive pulmonary disease, history of smoking, concomitant coronary artery bypass grafting, and all indicator variables for missing values. ${ }^{1-3}$ The concordance obtained with this model was represented by a $\mathrm{C}$ statistic of 0.92 .

The patients were then sorted according to their individual propensity score and for some analyses were divided into five quintiles of equal numbers of patients for comparison of repair versus replacement among closed propensity-matched patients.

Is survival better after mitral valve repair than after replacement? To answer this question, initial nonparametric estimates of survival were obtained by the Kaplan-Meier method. A parametric method was used to resolve the number of phases of instantaneous risk of death (hazard function) and to estimate its shaping parameters. ${ }^{4}$ Exploratory analyses of the variables in Appendix III included correlation analysis, stratified life table analyses, and decile risk analysis of ordinal and continuous variables to deter-

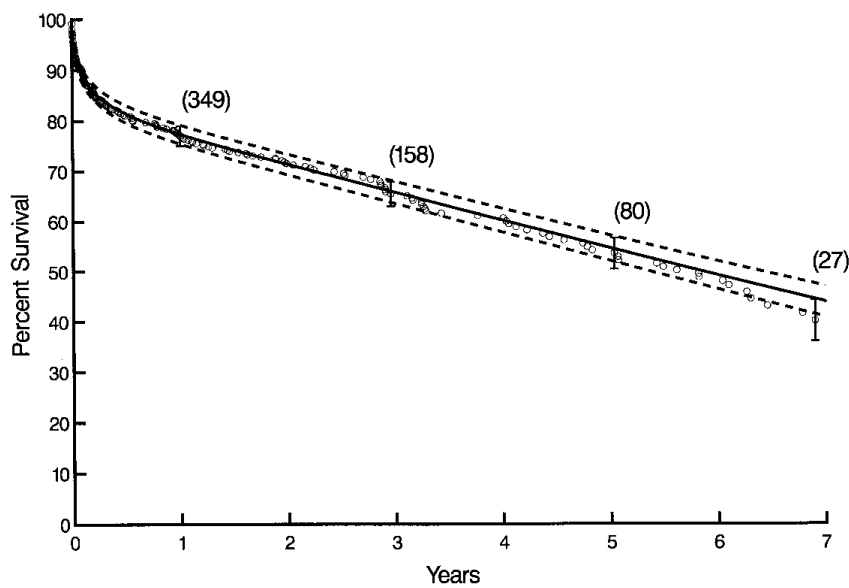

Figure 2. Survival after mitral valve surgery for all patients with ischemic mitral regurgitation. Each symbol represents a death according to Kaplan-Meier estimator. Vertical bars enclose asymmetric $68 \%$ confidence limits. Solid lines represent parametric survival estimates; these are enclosed between dashed $68 \%$ confidence limits. Numbers in parentheses are numbers of patients traced beyond that point.

mine possible transformations of scale needed to calibrate properly the variables to survival. Thereafter multivariable analysis was performed in the hazard function domain. In all analyses we forced the variable mitral valve repair versus mitral valve replacement and the propensity score. Details of the methods for managing missing values for variables and for the strategies of variable selection are given in Appendix II.

Which patients benefit from which procedure? The overall multivariable survival equation was solved twice for each patient, once as though the patient's mitral valve had been replaced and once again as though a repair had been performed (simulation). The difference between predicted 7-year survivals for these two strategies was compared. A positive difference was interpreted as a repair benefit, and a negative difference was interpreted as a replacement benefit. The comparison included multiple linear regression of the 7-year survival differences. Details of this analysis are given in Appendix II.

Analysis of echocardiographic features. Lateral wall motion abnormality and complex regurgitant jet direction were both risk factors. Their correlates were explored with multivariable logistic regression by the techniques described previously.

Is mitral valve repair durable? Durability of mitral valve repair was assessed by the time-related event mitral valve replacement for recurrent mitral regurgitation. We considered a repair failure to have occurred when the repair was completed and then assessed, generally by removal of cardiopulmonary bypass, with the finding of important residual mitral valve regurgitation. If this failure resulted in mitral valve replacement, it was called a repair failure; these few cases were carried in the mitral valve repair group throughout the analyses according to the strategy of intent to treat.

Presentation. Mortality and survival estimates are accompanied by an asymmetric $68 \%$ confidence interval, comparable to $\pm 1 \mathrm{SE}$. 
TABLE 4. Factors associated with the likelihood of mitral valve repair rather than replacement

\begin{tabular}{|c|c|c|}
\hline Factor & Logistic coefficient $( \pm$ SD) & $\boldsymbol{P}$ \\
\hline \multicolumn{3}{|l|}{ Clinical status } \\
\hline Lower NYHA functional class* & $-1.51 \pm 0.55$ & .006 \\
\hline Nonemergency surgery & $1.71 \pm 0.45$ & .0002 \\
\hline \multicolumn{3}{|l|}{ Left ventricular and mitral valve morphology } \\
\hline Isolated functional mitral regurgitation & $1.45 \pm 0.29$ & $<.0001$ \\
\hline Decreasing degree of regurgitationt & $-1.14 \pm 0.30$ & .0001 \\
\hline \multicolumn{3}{|l|}{ Coronary disease } \\
\hline ITA grafting & $0.78 \pm 0.32$ & .02 \\
\hline
\end{tabular}

Intercept for model, 4.78; C statistic, 0.82 .

*Natural logarithmic transformation of NYHA class (In[NYHA class]).

tNegative sign indicates decreasing likelihood of mitral valve repair and increasing likelihood of replacement.

TABLE 5. Distribution of patient and operative characteristics across propensity-matched quintiles

\begin{tabular}{|c|c|c|c|c|c|}
\hline \multirow[b]{2}{*}{ Variable } & \multicolumn{5}{|c|}{ Quintile } \\
\hline & $\mathrm{I}(\%, \mathrm{n}=96)$ & II $(\%, \mathbf{n}=96)$ & III $(\%, n=97)$ & IV $(\%, \mathbf{n}=96)$ & $V(\%, n=97)$ \\
\hline NYHA functional class IV & 67 & 43 & 29 & 34 & 9 \\
\hline Emergency surgery & 32 & 5 & 1 & 0 & 0 \\
\hline Severe (grade 4) mitral regurgitation & 86 & 71 & 61 & 30 & 3 \\
\hline Functional mitral regurgitation & 19 & 56 & 78 & 88 & 93 \\
\hline Infarcted papillary muscle without rupture & 49 & 38 & 19 & 11 & 5 \\
\hline Ruptured papillary muscle & 32 & 5 & 3 & 1 & 2 \\
\hline Use of ITA graft & 11 & 31 & 44 & 52 & 70 \\
\hline Surgeon A & 25 & 37 & 37 & 42 & 29 \\
\hline Surgeon B & 14 & 12 & 8 & 12 & 15 \\
\hline Mitral valve repair & 42 & 84 & 93 & 96 & 97 \\
\hline
\end{tabular}

\section{Results}

Were Patients Undergoing Mitral Valve Repair Similar to Those Undergoing Replacement?

The characteristics of patients undergoing valve repair and valve replacement differed (Tables 1 and 2). Factors associated with a greater likelihood of mitral valve repair versus replacement included nonemergency surgery, isolated functional mitral regurgitation, and use of ITA grafting. Factors associated with replacement were higher New York Heart Association (NYHA) functional class and more severe regurgitation (Table 4). When identifiers for surgeons were entered, two surgeons were found, after adjustment for patient factors, to be more likely to repair than to replace the valve $(P \leq .01, \mathrm{C}$ statistic $=0.88$ ), but no factors became statistically significant.

\section{Is Survival Better After Mitral Valve Repair Than After Replacement?}

The answer to the question of survival was not simple but depended on patient characteristics. Various lines of evidence for this answer are detailed here and are summarized in Appendix IV.

Overall survival. Fifty-four patients $(11 \%$, confidence interval 9\%-13\%) died in the hospital. Operative mortality rate (including those dying within 30 days) was 13\% (confidence interval $11 \%-14 \%$ ). Time-related survivals were $77 \%$ at 1 year and $55 \%$ at 5 years (Figure 2).

\section{Propensity-Matched Comparison}

Among propensity-matched patients in quintile I, survivals were similar after mitral valve repair and replacement (Figure 3, A). In quintile II (Figure 3, B) and particularly in quintiles III through V (Figure 3,C), however, which contained progressively fewer complex conditions and sicker patients (Table 5), repair afforded a survival advantage.

\section{Propensity and Risk-Adjusted Comparison}

After adjustment for dissimilarities in patient characteristics between those undergoing mitral valve repair versus replacement by propensity score, risk factors for early mortality (the dominant phase of hazard, extending to about 1 year) included older age, renal dysfunction, increasing NYHA functional class, greater left ventricular dysfunction, and, specifically, mitral valve replacement versus mitral valve repair (Table 6). However, the beneficial effect of repair was reduced if the ITA was not used for coronary revascularization, if a complex regurgitant jet pattern was 

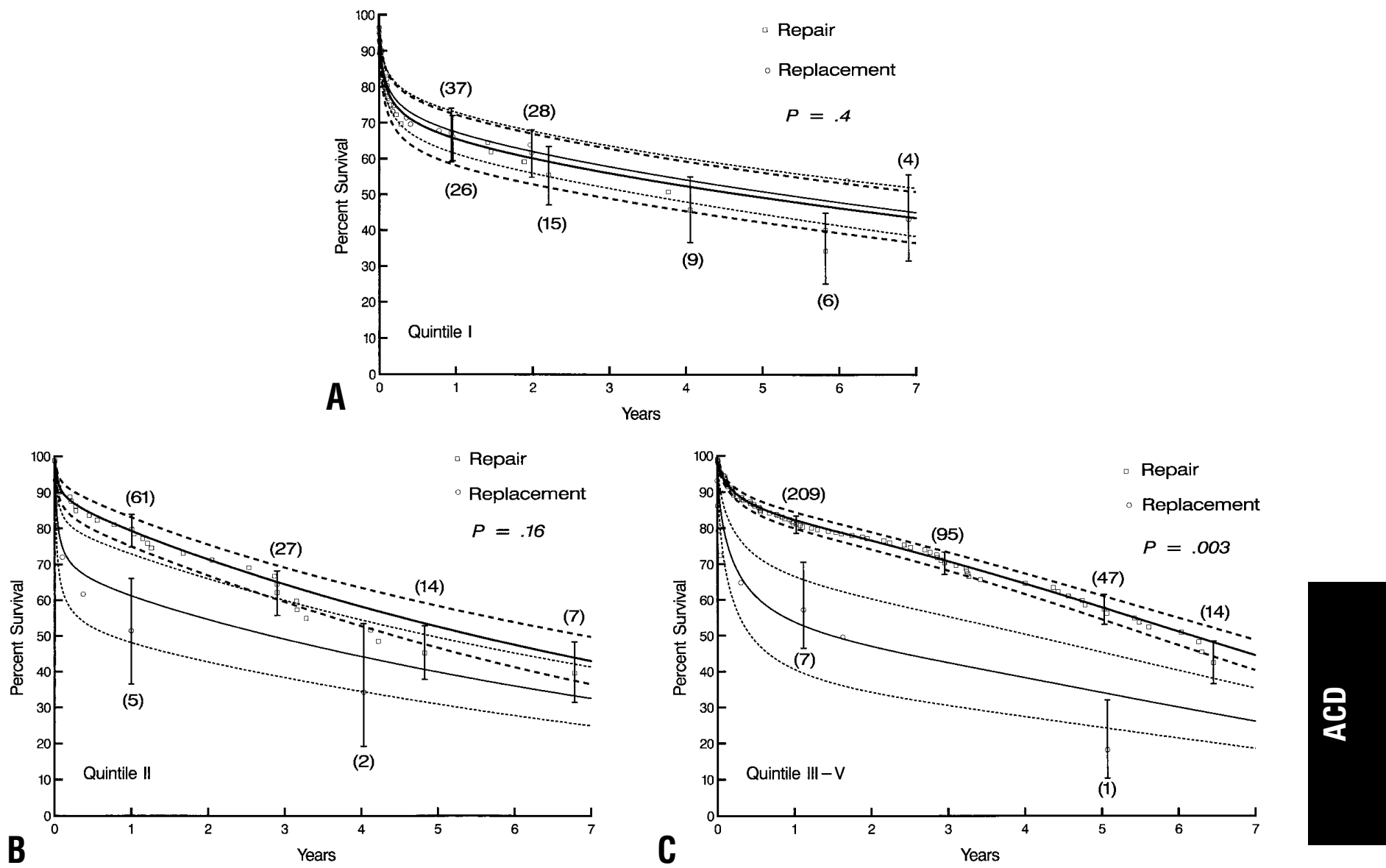

Figure 3. Survival for matched quintiles after mitral valve repair and mitral valve replacement. Because of the small number of patients with mitral valve replacement in quintiles III through $\mathrm{V}$, these quintiles are grouped together. Presentation follows format of Figure 2. P values are for log-rank test. A, Quintile I; B, quintile II; C, quintiles III through V.

present on echocardiography, or if bovine pericardium was used for the annuloplasty. Figure 4 illustrates the riskadjusted influence of repair versus replacement in the presence and absence of a complex regurgitant jet and lateral wall motion abnormality. A complex regurgitant jet was common among patients with an infarcted papillary muscle without rupture and those without severe left anterior descending coronary artery disease (Appendix I, Table 1).

Late survival was reduced among patients in atrial fibrillation or with impaired renal function. Survival was better among patients with an inferior wall motion abnormality. We were unable to demonstrate an effect of repair versus replacement in this hazard phase except among patients with a lateral wall motion abnormality, whose survival was worse with repair. Correlates of lateral segment wall motion abnormality included absence of right coronary artery disease (Appendix I, Table 2). Thus, although survival was generally better if there was a ruptured papillary muscle rather than an infarcted papillary muscle or isolated func- tional mitral regurgitation, other risk factors accounted adequately for the observed overall differences (Figure 5).

Surgeons who performed fewer of these operations were more likely to operate on an emergency basis (21\% vs $6 \%$, $P<.0001)$ and more likely to replace the mitral valve $(30 \%$ vs $16 \%$ ) than surgeons with higher volumes. However, neither surgeon volume nor identity influenced early $(P=.5)$ or late $(P=.9)$ survival.

\section{Which Patients Benefit From Which Procedure?}

When we simulated both valve repair and valve replacement by solving the multivariable equation twice for each patient, the predicted difference in 7-year survival showed a repair benefit for $66 \%$ of patients (Figure 6, $A$ ). This repair benefit was true for both the actual repair and actual replacement groups (Figure 6, $B$ ). The patients with the most complex and severe conditions did not appear to benefit from mitral valve repair; indeed, their 7-year survival was better with replacement. However, this apparent advantage to mitral valve replacement was partially neutralized if patients 

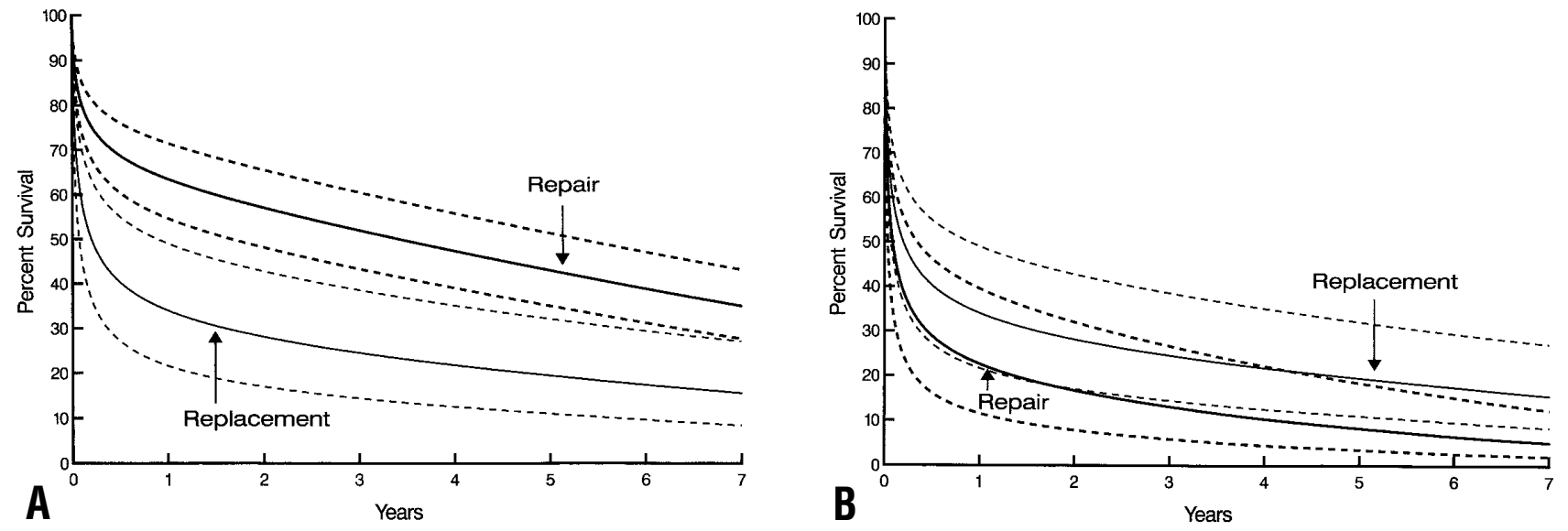

Figure 4. Predicted survivals after mitral valve repair and replacement for two different patients according to multivariable equation in Table 6 . Figure shows impacts of complex regurgitant jet and lateral wall motion abnormality on survival. A, 65-year-old patient with moderate left ventricular dysfunction, no renal dysfunction, no inferior wall motion abnormality, requiring emergency surgery. No ITA graft was used, there was no complex regurgitant jet, and there was no lateral wall motion abnormality. Survival would be better with valve repair than with valve replacement. B, Similar patient but with complex regurgitant jet and lateral wall motion abnormality. Survival predicted to be generally poor, with no advantage of repair.

TABLE 6. Multivariable analyses of death with all patients

\begin{tabular}{|c|c|c|c|c|}
\hline \multirow[b]{3}{*}{ Incremental risk factors } & \multicolumn{4}{|c|}{ Hazard phase } \\
\hline & \multicolumn{2}{|c|}{ Early } & \multicolumn{2}{|c|}{ Late } \\
\hline & Coefficient $( \pm$ SD) & $\boldsymbol{P}$ & Coefficient ( \pm SD) & $\boldsymbol{P}$ \\
\hline \multicolumn{5}{|l|}{ Demographic characteristics } \\
\hline Older age ${ }^{*}$ & $0.73 \pm 0.18$ & $<.0001$ & - & \\
\hline \multicolumn{5}{|l|}{ Clinical status } \\
\hline Higher NYHA functional class $†$ & $0.68 \pm 0.15$ & $<.0001$ & - & \\
\hline \multicolumn{5}{|l|}{ Cardiac comorbidity } \\
\hline Increasing severity of wall motion abnormality $\ddagger$ & $0.069 \pm 0.022$ & .001 & - & \\
\hline Wall motion abnormality site inferior§ & - & & $-0.85 \pm 0.28$ & .002 \\
\hline Wall motion abnormality site lateral in patients with repair & - & & $0.79 \pm 0.29$ & .006 \\
\hline Preoperative atrial fibrillation & - & & $1.05 \pm 0.26$ & $<.0001$ \\
\hline \multicolumn{5}{|l|}{ Valve pathophysiology } \\
\hline Complex jet direction in repair patients & $1.21 \pm 0.36$ & .0007 & - & \\
\hline \multicolumn{5}{|l|}{ Noncardiac comorbidity } \\
\hline Higher preoperative creatinine & $0.26 \pm 0.061$ & $<.0001$ & - & \\
\hline Higher preoperative blood urea nitrogenף & - & & $0.70 \pm 0.25$ & .005 \\
\hline \multicolumn{5}{|l|}{ Operation } \\
\hline Mitral valve repair§ & $-2.12 \pm 0.52$ & $<.0001$ & $0.11 \pm 0.62$ & .9 \\
\hline Use of bovine pericardial ring in patients with repair & $0.48 \pm 0.27$ & .07 & - & \\
\hline Absence of ITA grafting in patients with repair & $1.22 \pm 0.41$ & .003 & - & \\
\hline Propensity score & $1.08 \pm 0.62$ & .08 & $0.18 \pm 0.99$ & .9 \\
\hline
\end{tabular}

*Exponential transformation of age in years (exp[age/50]).

TNYHA functional classes I through $V$, where class $V$ is equivalent to class IV with emergency surgery.

¥Grades are as follows: 1 , normal; 2 , mild; 3 , moderate; 4 , severe, square transformation.

$\S N$ gative coefficient indicates beneficial association.

Interaction term.

१Natural logarithmic transformation of blood urea nitrogen in milligrams per deciliter (In[blood urea nitrogen]).

1132 The Journal of Thoracic and Cardiovascular Surgery • December 2001 


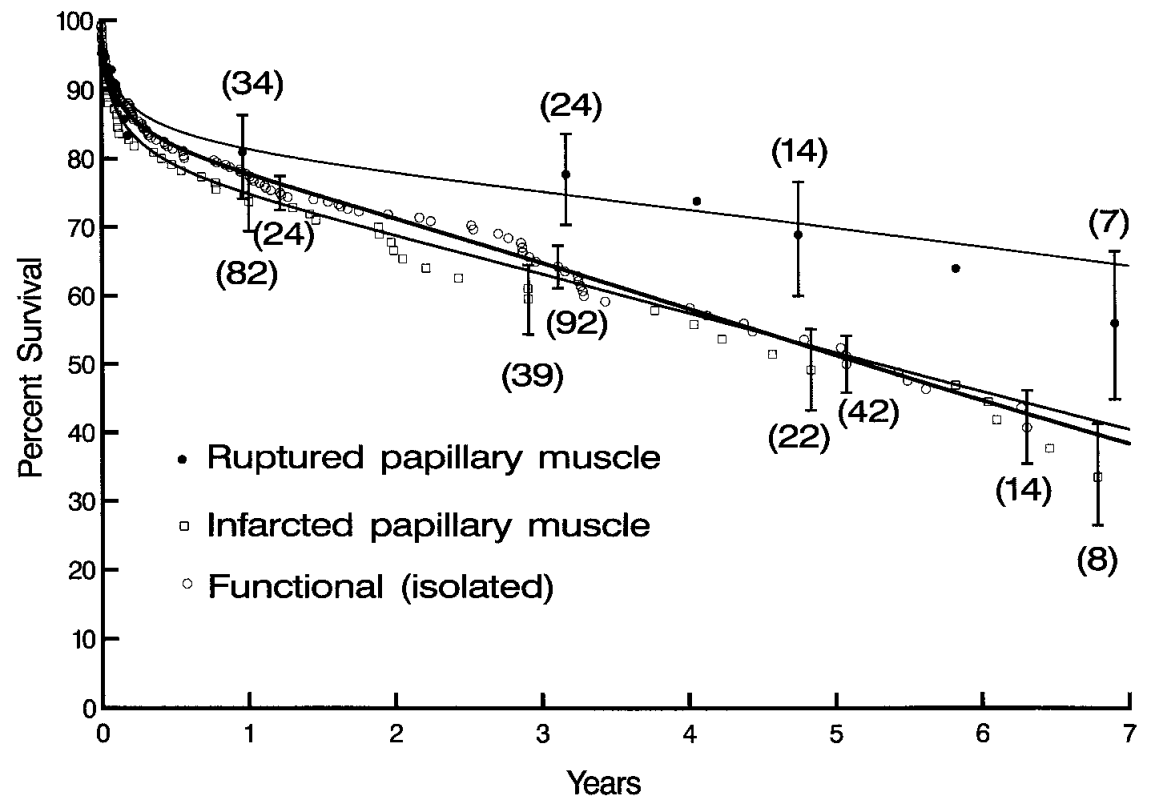

Figure 5. Survival according to cause of ischemic mitral regurgitation. According to univariate analysis, patients with papillary muscle rupture appear to have superior survival. Depiction as in Figure 2.

undergoing repair received an ITA graft and an annuloplasty by a technique other than a bovine pericardial strip (see Appendix V).

\section{Is Mitral Valve Repair Durable?}

At the end of repair, 6 patients were found to have at least moderate residual mitral regurgitation and were returned to cardiopulmonary bypass for replacement of the valve. When these cases were added as repair failures, freedoms from mitral valve reoperation were $98 \%$ at 30 days, $96 \%$ at 1 year, and $91 \%$ at 5 years (Figure 7 ).

\section{Discussion}

\section{Classification of Ischemic Mitral Regurgitation}

All patients in this report had mitral regurgitation caused by a previous myocardial infarction. From analysis of echocardiograms and operative reports, we were able to classify patients into three groups according to the mechanism of regurgitation: ruptured papillary muscle, infarcted papillary muscle without rupture, and functional ischemic mitral regurgitation. Others have proposed similar classification schemes. ${ }^{5-11}$ Differences among these schemes create confusion. We propose a simple system of classification that encompasses all patients with ischemic mitral regurgitation caused by previous myocardial infarction. This system should permit uniform reporting of surgical results and meaningful comparisons between different series. Furthermore, in this system, the mechanism of mitral regurgitation dictates the repair techniques used when mitral reconstruction is attempted.
It is of particular importance, however, to verify that the mitral regurgitation is, in fact, caused by a myocardial infarction. Most patients with concomitant mitral regurgitation and coronary artery disease do not have ischemic mitral regurgitation. Rather, they have a primary mitral valve pathologic condition (degenerative or rheumatic) and coexisting coronary artery disease.

The minority of patients with ischemic mitral regurgitation have pathologic changes of the papillary muscle. Papillary muscle rupture, which is usually an acute and catastrophic event, has a different presentation from papillary muscle infarction with an elongated but intact papillary muscle. Repair techniques for these two conditions differ. $9,10,12$ Although these conditions represent end points of the same pathologic process, it is thus useful to consider them as distinct entities.

Most patients with ischemic mitral regurgitation have functional ischemic mitral regurgitation. In such cases, the mitral leaflets and subvalvular apparatus appear structurally normal on echocardiography and direct inspection. The leaflets fail to coapt during ventricular systole and may appear restricted, producing a regurgitant jet that is usually central but occasionally eccentric (complex). $5,6,13$ We agree with others that this entity should be termed functional ischemic mitral regurgitation. The term papillary muscle dysfunction ${ }^{7}$ should be used with caution; although papillary muscle dysfunction may contribute to transient mitral regurgitation in patients with intermittent ischemia, it does not explain the mechanism of functional mitral regurgitation.

The mechanism of functional ischemic mitral regurgitation has been debated. It is probably a complex entity pro- 

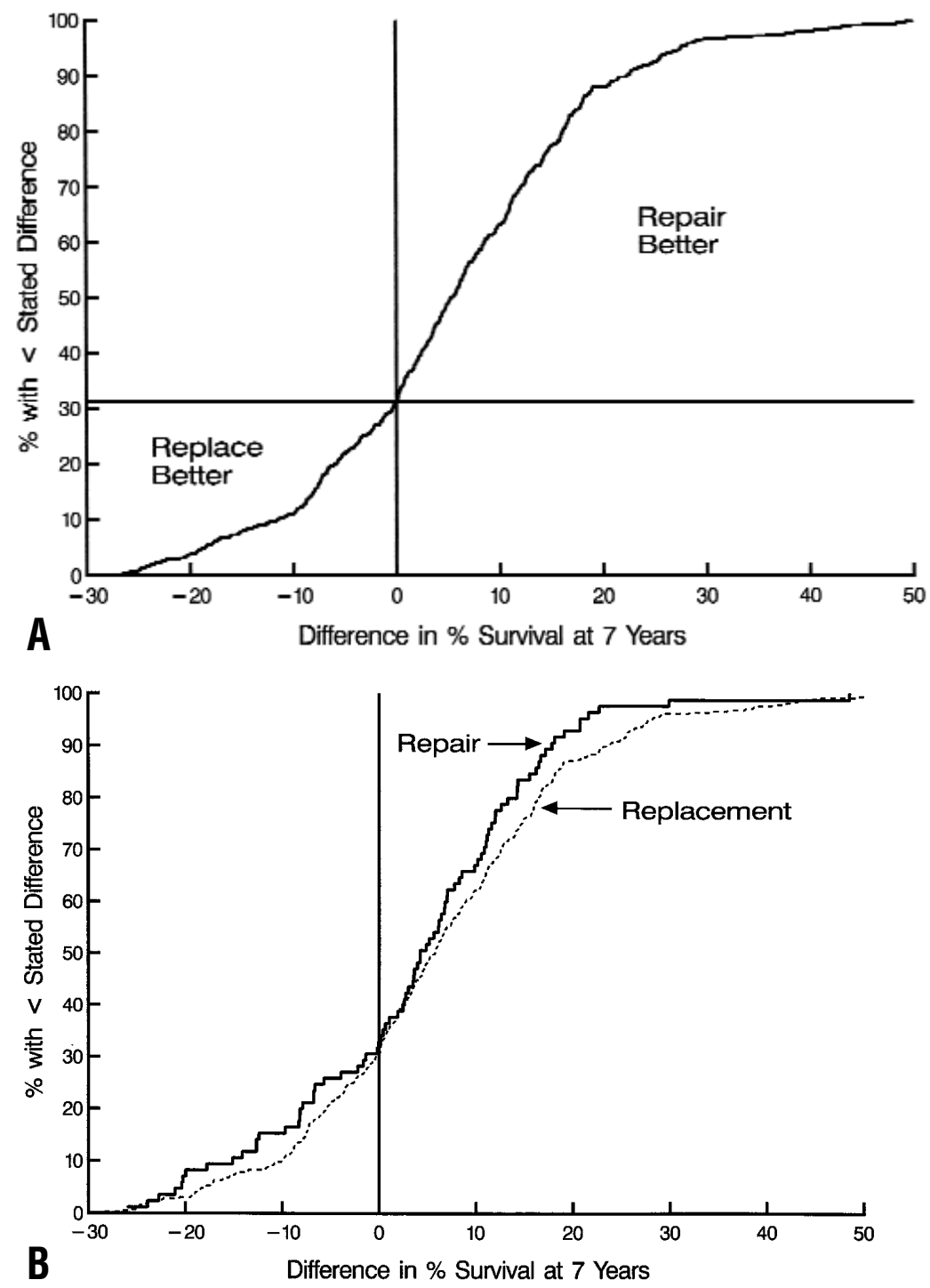

Figure 6. Cumulative distribution of differences in 7-year survival between mitral valve repair and replacement. Patients to right of 0 difference are predicted to benefit from mitral valve repair. $A, 0$ verall cumulative distribution; B, cumulative distribution of survival differences for patients with actual repair (solid line) and actual replacement (dashed line).

duced by changes in annular, ventricular, and papillary muscle geometry and function. ${ }^{11,14,15}$ The mechanism may differ from patient to patient, depending on the site and extent of myocardial infarction. Pathologic examinations by Bulkley and Roberts ${ }^{16}$ suggest that isolated annular dilatation is a rare cause of mitral regurgitation; however, others believe that annular dilatation is an important component of functional ischemic mitral regurgitation. ${ }^{6,11,17,18}$ The primary pathologic condition may involve alterations in ventricular and papillary muscle geometry, producing a tethering effect on the mitral leaflets. ${ }^{5,8,11}$ Although the mechanism of functional ischemic mitral regurgitation is unclear, the most important point is that these patients have normal mitral leaflets and subvalvular apparatus, which allows treatment by annuloplasty alone. $5,6,8,13$

The mechanism of ischemic mitral regurgitation has been investigated in several animal models. In an acute sheep model, Gorman found that large posterior infarction caused asymmetric annular dilatation and changes in papillary muscle geometry. ${ }^{19}$ Both posterior papillary muscle infarction and left ventricular dilatation were necessary to produce ischemic mitral regurgitation; left ventricular dilatation alone did not produce mitral regurgitation. ${ }^{20}$ An elegant study from Stanford University of acute ischemic mitral regurgitation suggested that early systolic annular dilatation, shape change, and altered posterior papillary 


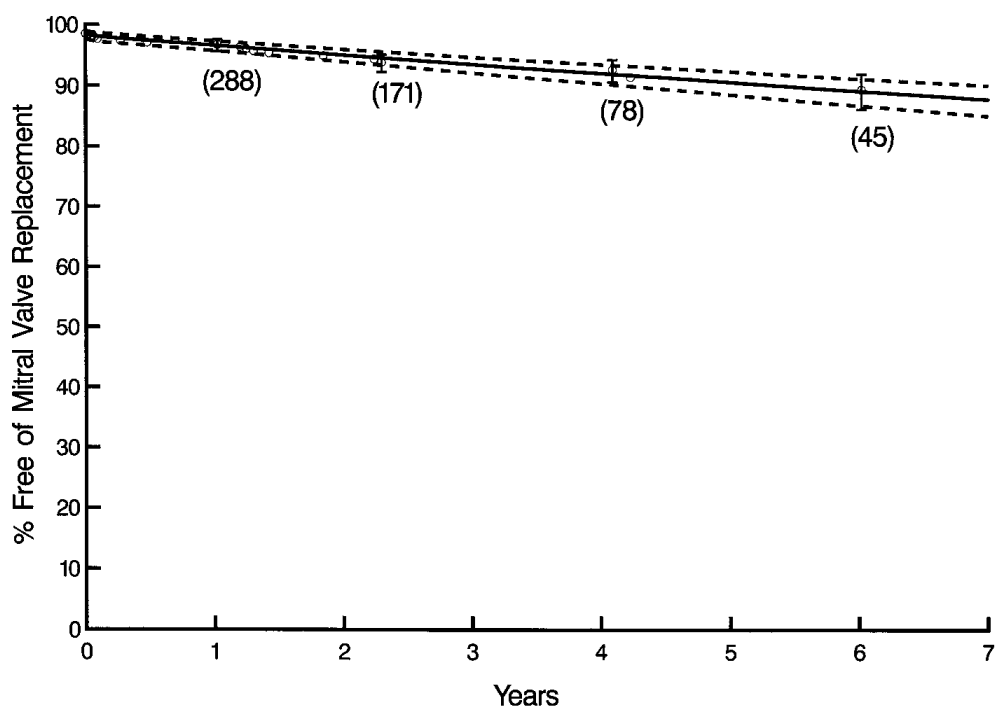

Figure 7. Freedom from mitral valve replacement after mitral valve repair. Depiction as in Figure 2.

muscle motion are the primary mechanisms of acute ischemic mitral regurgitation. ${ }^{21}$ Experimental studies in other models suggest roles for alterations in left ventricular shape $^{22}$ and changes in distance from the papillary muscles to the anulus. ${ }^{23}$ These studies of acute ischemic mitral regurgitation in animal models are limited in their ability to explain the mechanism of human ischemic mitral regurgitation. Nevertheless, they demonstrate that functional ischemic mitral regurgitation is probably more complicated in its pathogenesis than simple annular dilatation.

\section{Implications of Differences Among Patients Undergoing Mitral Valve Repair Versus Replacement}

Patients who underwent a mitral valve repair differed in important respects from many of the patients who underwent replacement. We therefore approached this potential confounding of the comparison by using the propensity score. ${ }^{1-3}$ This is one of a suite of balancing scores whereby patients can be matched multivariably (balanced) at the expense of imbalanced numbers of patients from each group in each comparison (Table 5). The imbalance in numbers renders the comparison in quintiles III through $\mathrm{V}$ tenuous. This extreme imbalance revealed that we were dealing with a wide spectrum of disease in this group of patients and that less ill patients with fewer sequelae of this myocardial damage whose surgery was elective preferentially underwent repair. We believe that our use of the propensity score as a covariable in our modeling and our extensive subgroup and interaction analyses adjusted well for these imbalances (see Appendix III and Appendix IV for details).

\section{Mitral Valve Repair Versus Replacement}

Patients with ischemic mitral regurgitation have an unfavorable prognosis, with poor survival relative to patients with other causes of mitral dysfunction., 6,24 It is therefore important to determine which factors influence early and late survival for risk stratification and alteration of surgical approach that might improve survival.

We documented several risk factors for early and late death after surgical treatment of ischemic mitral regurgitation. These included such general factors as older age, advanced NYHA functional class, severe left ventricular dysfunction, preoperative atrial fibrillation, and renal dysfunction. In addition, patients with inferior wall motion abnormalities, corresponding to right coronary artery infarcts, had better survival than did patients with other wall motion abnormalities. Others have reported similar findings. 6,7

\section{Which Patients Benefit From Repair?}

The previously discussed information can be used for risk stratification, but does not afford the surgeon the opportunity to influence outcome by surgical technique. We therefore asked the specific question, "For whom is repair better than replacement as treatment for ischemic mitral regurgitation?"

The answer is that repair confers a survival advantage for most patients with ischemic mitral regurgitation. The impact of mitral valve repair was investigated with a variety of methods. Propensity matching was invaluable in the analysis, because there was a great deal of interaction between it and outcome. Across all propensity-matched quintiles, mitral valve replacement resulted in a fairly uniform outcome, with poor long-term survival independent of patient status. In contrast, mitral valve repair produced a modulated result across the quintiles. Thus patients who underwent elective surgery and had a more stable condition derived a survival benefit from mitral valve repair (see Appendix IV).

A more detailed examination of patients in the repair group revealed that they had reduced survival if they had a lat- 
eral infarct or a complex regurgitant jet. The reason for these findings is not entirely clear but may relate to the extent of the wall motion abnormality and difficulty in achieving a perfect repair in cases of complex regurgitant jets. Patients who underwent mitral valve repair had improved survival if they had an ITA graft and a formal annuloplasty band or ring (rather than a bovine pericardial strip).

Several investigators have suggested that repair is better than replacement for patients with ischemic mitral regurgitation. ${ }^{7,17}$ Others, however, have documented equivalent late survivals after repair and replacement. ${ }^{5,24}$ Chordal preservation at mitral valve replacement may be an important means of improving survival. ${ }^{5}$ Cohn and colleagues ${ }^{6}$ and Dion and associates $^{14}$ concluded that the pathophysiologic mechanism of mitral regurgitation and the mode of presentation of the patient were more important determinants of outcome than was the surgical technique. In an earlier analysis of a smaller number of patients, we found better survival after repair among patients with leaflet prolapse than among those with functional ischemic mitral regurgitation. ${ }^{10}$ This study suggests a far more complicated interaction, however, with important impacts on results of patient presentation, specific regurgitant and wall motion abnormalities, and surgical technique.

Surgical techniques for mitral valve repair in patients with ischemic mitral regurgitation have been described by others. 5,6,8,10,12 Papillary muscle rupture was repaired by papillary muscle reimplantation or occasionally by resection of a prolapsing portion of the posterior leaflet. Papillary muscle infarction was repaired by papillary muscle shortening. Functional ischemic mitral regurgitation was repaired by annuloplasty alone. We prefer to use an undersized annuloplasty, and $79 \%$ of patients who underwent mitral valve repair had an annuloplasty that was $30 \mathrm{~mm}$ or smaller. Others have also reported excellent results with an undersized annuloplasty for functional ischemic mitral regurgitation. ${ }^{9}, 13,15$ Frater $^{13}$ believes that the undersized annuloplasty compensates for posterior left ventricular dilatation. Bolling and colleagues ${ }^{15}$ suggest that an undersized annuloplasty may in time result in reversal of ventricular remodeling. The technique of annuloplasty is important. Bovine pericardial annuloplasty jeopardized late survival, and others have demonstrated that ring annuloplasty is superior to suture annuloplasty for patients with ischemic mitral regurgitation. ${ }^{9}$ Experimental data suggest that posterior annuloplasty may be sufficient to correct functional ischemic mitral regurgitation. ${ }^{21}$ Our own data confirm this, because survivals were similar with the Cosgrove-Edwards annuloplasty band and the Carpentier-Edwards annuloplasty ring.

Although some favor cardiac transplantation for certain subsets of patients with ischemic mitral regurgitation, ${ }^{24}$ we have not used this strategy. Contemporary 5- and 10-year survivals after cardiac transplantation are $68 \%$ and $46 \%$, rendering this an imperfect option. ${ }^{25}$ In addition, most patients in this series were elderly, making them unlikely candidates for transplantation.

\section{Limitations}

This was a nonrandomized clinical study. By using the propensity score, we attempted to adjust the multivariable analyses of outcomes for nonrandom selection bias related to choice of valvular procedure.

The need for surgical intervention for patients with moderate (2+) mitral regurgitation remains a matter of debate and should be the subject of a prospective study. The question cannot be addressed by this clinical study.

Serial echocardiographic follow-up assessment of mitral valve function was unavailable for most patients who underwent mitral valve repair. Therefore the data do not allow discrimination of patients who had recurrent mitral valve dysfunction but did not undergo reoperation.

The end points investigated in this study were death and mitral valve reoperation. We did not analyze other valve-related complications, all of which have been thoroughly documented in the literature for mitral valve repair and replacement.

We were unable to determine from review of all operative reports which patients with mitral valve replacement had preservation of all or part of the subvalvular apparatus. The impact of this surgical technique therefore could not be analyzed. Only a single patient in this study had an Alfieri stitch. The impact of the Alfieri stitch in ischemic mitral regurgitation is the subject of an ongoing study.

Finally, patients with intermittent ischemic mitral regurgitation treated by coronary revascularization alone were not included in this analysis.

\section{Clinical Inferences and Decision-Making}

Patients who require mitral valve surgery for ischemic mitral regurgitation can be classified by echocardiography and direct inspection as having a ruptured papillary muscle, infarcted but unruptured papillary muscle, or functional ischemic mitral regurgitation. Late survival is poor for all groups, with most patients dying within 7 years of surgery. However, choice of surgical procedure has an important impact on late survival. Most patients derive a survival advantage from mitral valve repair rather than replacement. Among the most severely ill patients, the survival benefit of mitral valve repair is diminished. When mitral valve repair is performed, a formal annuloplasty should be used, and left anterior descending disease should be treated by ITA grafting.

We thank Karen Mrazeck for assembling and verifying the clinical data and performing the follow-up; John Hendricks, Linda DiPaola, and Maura Schnauffer for constructing the data set; and Lucinda Mitchin for expert secretarial assistance.

\section{References}

1. Rosenbaum PR, Rubin DB. The central role of the propensity score in observational studies for causal effects. Biometrika. 1983;70:41-55. 
2. Rubin DB. Estimating causal effects from large data sets using propensity scores. Ann Intern Med. 1997;127(8 Pt 2):757-63.

3. Cook EF, Goldman L. Performance of tests of significance based on stratification by a multivariate confounder score or by a propensity score. J Clin Epidemiol. 1989;42:317-24.

4. Blackstone EH, Naftel DC, Turner ME Jr. The decomposition of timevarying hazard into phases, each incorporating a separate stream of concomitant information. J Am Stat Assoc. 1986;81:615-24.

5. Oury JH, Cleveland JC, Duran CG, Angell WW. Ischemic mitral valve disease: classification and systemic approach to management. $J$ Card Surg. 1994;9(2 Suppl):262-73.

6. Cohn LH, Rizzo RJ, Adams DH, Couper GS, Sullivan TE, Collins JJ $\mathrm{Jr}$, et al. The effect of pathophysiology on the surgical treatment of ischemic mitral regurgitation: operative and late risks of repair versus replacement. Eur J Cardiothorac Surg. 1995;9:568-74.

7. Rankin JS, Feneley MP, Hickey MS, Muhlbaier LH, Wechsler AS, Floyd RD, et al. A clinical comparison of mitral valve repair versus valve replacement in ischemic mitral regurgitation. J Thorac Cardiovasc Surg. 1988;95:165-77.

8. David TE. Techniques and results of mitral valve repair for ischemic mitral regurgitation. J Card Surg. 1994;9:274-7.

9. Czer LS, Maurer G, Trento A, DeRobertis M, Nessim S, Blanche C, et al. Comparative efficacy of ring and suture annuloplasty for ischemic mitral regurgitation. Circulation. 1992;86(5 Suppl):II-46-52.

10. Hendren WG, Nemec JJ, Lytle BW, Loop FD, Taylor PC, Stewart RW, et al. Mitral valve repair for ischemic mitral insufficiency. Ann Thorac Surg. 1991;52:1246-52.

11. Dion R. Ischemic mitral regurgitation: when and how should it be corrected? J Heart Valve Dis. 1993;2:536-43.

12. Yun KL, Miller DC. Mitral valve repair: when is it preferable to replacement? Cardiol Rev. 1993;1:187-99.

13. Frater RW. Ischemic mitral regurgitation [letter]. J Heart Valve Dis. 1993;2:706.

14. Dion R, Benetis R, Elias B, Guennaoui T, Raphael D, van Dyck M, et al. Mitral valve procedures in ischemic regurgitation. J Heart Valve Dis. 1995;4 Suppl 2:S124-31.

15. Bolling SF, Pagani FD, Deeb GM, Bach DS. Intermediate-term outcome of mitral reconstruction in cardiomyopathy. $J$ Thorac Cardiovasc Surg. 1998;115:381-8.

16. Bulkley BH, Roberts WC. Dilatation of the mitral anulus: a rare cause of mitral regurgitation. Am J Med. 1975;59:457-63.

17. Kay GL, Kay JH, Zubiate P, Yokoyama T, Mendez M. Mitral valve repair for mitral regurgitation secondary to coronary artery disease. Circulation. 1986;74(3 Pt 2):I-88-98.

18. Izumi S, Miyatake K, Beppu S, Park YD, Negata S, Kinoshita N, et al. Mechanism of mitral regurgitation in patients with myocardial infarction: a study using real-time two-dimensional Doppler flow imaging and echocardiography. Circulation. 1987;76:777-85.

19. Gorman JH, Gorman RC, Jackson BM, Hiramatsu Y, Gikakis N, Kelley ST, et al. Distortions of the mitral valve in acute ischemic mitral regurgitation. Ann Thorac Surg. 1997;64:1026-31.

20. Llaneras MR, Nance ML, Streicher JT, Linden PL, Downing SW, Lima JA, et al. Pathogenesis of ischemic mitral insufficiency. J Thorac Cardiovasc Surg. 1993;105:439-43.

21. Glasson JR, Komeda M, Daughters GT, Bolger AF, Karlsson MO, Foppiano LE, et al. Early systolic mitral leaflet "loitering" during acute ischemic mitral regurgitation. J Thorac Cardiovasc Surg. 1998; 116:193-205.

22. Kono T, Sabbah HN, Rosman H, Alam M, Jafri S, Goldstein S. Left ventricular shape is the primary determinant of functional mitral regurgitation in heart failure. J Am Coll Cardiol. 1992;20: 1594-8.

23. Otsuji Y, Handschumacher MD, Schwammenthal E, Jiang L, Song JK, Guerrero JL, et al. Insights from three-dimensional echocardiography into the mechanism of functional mitral regurgitation: direct in vivo demonstration of altered leaflet tethering geometry. Circulation. 1997;96:1999-2008.

24. Hausmann H, Siniawski H, Hetzer R. Mitral valve reconstruction and replacement for ischemic mitral insufficiency: seven years' follow-up. J Heart Valve Dis. 1999;8:536-42.

25. Robbins RC, Barlow CW, Oyer PE, Hunt SA, Miller JL, Reitz BA, et al. Thirty years of cardiac transplantation at Stanford University. $J$ Thorac Cardiovasc Surg. 1999;117:939-51.

26. Baskerville JC, Toogood JH. Guided regression modeling for prediction and exploration of structure with many explanatory variables. Technometrics. 1982;24:9-17.

27. Altman DG, Andersen PK. Bootstrap investigation of the stability of a Cox regression model. Stat Med. 1989;8:771-83.

28. Breiman L. Bagging predictors. Machine Learning. 1996;26:123-40.

29. Blackstone EH, Kirklin JW. Recommendations for prophylactic removal of heart valve prostheses. J Heart Valve Dis. 1992;1: 3-14.

\section{Discussion}

Dr D. Craig Miller (Stanford, Calif). I commend Wierup and colleagues for a fine presentation of a complex data set and compliment them on this massive undertaking, which took 2 years to complete. This report is the best we can hope for in encompassing this challenging topic and finally gets rid, for the most part, of the problem of comparing apples and oranges, which we have faced for many years.

This is the largest report to date on surgically treated patients with ischemic mitral regurgitation, and it should be emphasized that this is a "clean" series in that all of these patients had causal ischemic mitral regurgitation as a consequence of coronary disease and not just incidental coronary artery disease, something which has confounded previous reports. Now that we have large numbers of patients analyzed by the unbelievable statistical prowess of Dr Blackstone, who has truly done statistical backflips in gleaning meaningful messages, what have we learned?

First, patients with ischemic mitral regurgitation treated either way have a soberingly poor 5- to 7-year prognosis. This sad fact, which concurs with previous honest reports, begs the question of whether transplantation might be a better option for suitable individuals.

Second, we now know that mitral annuloplasty, even if performed at the heralded Cleveland Clinic Foundation, does not confer immortality. Indeed, in the sickest quintile of patients there really was no difference in survival between repair and replacement. Why? Well, as always, it is probably patient selection first, patient selection second, and patient selection third, which brings up the possible presence of subtle patient referral or patient selection biases in this report. There probably is a difference in patient substrate between the patient with ischemic mitral regurgitation who has been on surgeon X's waiting list for 2 or 3 months and has an operation done during daylight hours and the patient who is airlifted in so that an emergency operation can be undertaken in the middle of the night. Dr Wierup, did you look for the influence of such possible bias by adjusting results by surgeon, or perhaps maybe even by the time of day or night that the operation commenced?

Is the take-home message really that the low-risk patients with "functional" ischemic mitral regurgitation, a central jet with Carpentier type I (or normal) leaflet motion, really do better after repair than they would have if they had received a valve replacement? This may well be the case, Dr Wierup, but because you do not know who had what type of replacement or what type of chorda-sparing replacement, how can we be sure the survival would not have been equivalent if the patients undergoing valve replacement had had complete or partial chordal preservation? For example, you stated that survivals were similar after valve replacement and repair in the sickest, 
highest-risk quintile of patients. Later, you mentioned that the survival advantage of repair was partially neutralized if the repair did not involve an ITA graft, or a Carpentier-Edwards ring or a Cosgrove annuloplasty band instead of vein grafting alone or nonring pericardial strip annuloplasty. Conversely, could the putative survival advantage of repair for the least sick, lowestrisk patients have been potentially neutralized if all or some of the chordae had been preserved in all the replacements?

Something predictable and reproducible is what we all want here, especially in the middle of the night in less than ideal circumstances, and maybe mitral valve replacement with total chordal preservation is the way to go in many cases. Given the dismal long-term survival of these patients, this patient substrate is an ideal indication for a tissue bioprosthesis, no matter the patient's age.

Third, if repair really is that much better than replacement, why wasn't this evident for the sickest patients? Indeed, I was even struck by the modest magnitude of survival advantage in the least sick quintiles. None of us can make a silk purse out of a sow's ear here, and I think that is the crux of the matter; but this sad news could be due to the challenging subset of cases with a "complex" mitral regurgitation jet. I think that this subgroup probably had the restricted systolic leaflet motion, or so-called Carpentier type III leaflet motion, and apical tethering of the leaflets. It is a much more complicated setting than simple annular dilatation and a central mitral regurgitation jet, where a small ring probably is adequate. Are you and your colleagues at the Clinic in such circumstances now adding other adjuncts to your repair techniques, such as a commissuroplasty or an Alfieri stitch? If so, where? In the posteromedial scallop or in the middle of the valve? What about actual leaflet elongation or extension procedures such as those performed by Kohl in Lund, Sweden, and in Toronto by Tirone David?

To sum up, none of us has all the answers yet, but this article sure helps.

Dr Wierup. Thank you, Dr Miller. Certainly these patients face a poor survival, and transplantation, as previously suggested by Houseman from Berlin, is an alternative.

We have not looked for the influence of different surgeons on the outcome, nor have we taken into account the time of day.

We are aware of the beneficial results shown by Dr David and colleagues for preservation of the subvalvular apparatus in mitral valve replacement, and our current practice is to preserve as much as possible of the subvalvular apparatus when we replace the valve. This information was not stated in some of the charts, however, and we elected not to analyze this aspect.

Regarding mitral valve replacement in the sickest patients, analyses showed slightly different survival patterns for replacement versus repair, with more early deaths and fewer later ones, resulting in no overall survival advantage.

Let me comment on the "complex jet." In our material $15 \%$ of the patients had a complex jet, which was frequently seen at the posteromedial commissure. Our current techniques are undersizing of the annuloplasty and commissuroplasty at the posteromedial commissure. We have not yet started with leaflet extension, but it could certainly be an alternative.

Dr Robert A. Dion (Leiden, The Netherlands). What is your rationale for adding a mitral valve procedure for patients with only moderate or fluctuating or intermittent mitral regurgitation?
Dr Wierup. We make sure that the patient has adequate preload and afterload, and if the regurgitation does increase to more than $2+$, we do not operate on the valve.

Dr Alain Carpentier (Paris, France). First of all, I congratulate you on this excellent presentation and pointing out the superiority of valve repair. Let me talk about just the patients with not as good a result in the group of very sick patients.

It was mentioned that a solution to that problem could be leaflet extension. I do not recommend leaflet extension for this particular group because it is just time-consuming, and for this particular subgroup of patients it will not be the solution. I would rather recommend downsizing the ring. Have you tried to downsize the annuloplasty in this particular group, which I think is a simple solution?

Dr Wierup. Yes, our current practice is to undersize in this entity.

\section{Appendix I}

\section{Wall Motion Abnormalities}

The sources of left ventricular wall motion data were, in order of preference, the intraoperative echocardiogram, preoperative transthoracic echocardiogram, and preoperative left ventriculogram. Five general ventricular segments were recorded (Figure 1). The anterior segment included anterior, anteroseptal, anterolateral, and anteroapical locations. The septal segment included septal, anteroseptal, and inferoseptal locations. The inferior segment included inferior, inferior-posterior, and inferior-septal locations. The lateral segment included lateral, posterolateral, and anterolateral locations. The posterior segment included posterior, posterolateral, and inferior-posterior locations. Thus when composite locations were encountered (eg, anteroseptal), abnormalities were recorded in both anterior and septal segments.

Each location was assessed as normal or abnormal. An abnormal assessment was recorded for findings of hypokinesis, akinesis, dyskinesis, or aneurysm.

Appendix I, TABLE 1. Correlates of complex regurgitant jet

\begin{tabular}{lcc}
\hline Factor & Logistic coefficient ( \pm SD) & $\boldsymbol{P}$ \\
\hline $\begin{array}{l}\text { Infarcted papillary muscle } \\
\text { without rupture }\end{array}$ & $0.95 \pm 0.30$ & .002 \\
$\begin{array}{l}\text { Absence of left anterior descending } \\
\text { coronary artery stenosis } \geq 70 \%\end{array}$ & $-0.61 \pm 0.31$ & .05 \\
\hline
\end{tabular}

Intercept for model, -1.71 ; C statistic, 0.67 .

Appendix I, TABLE 2. Correlates of lateral segment wall motion abnormality

\begin{tabular}{|c|c|c|}
\hline Factor & Logistic coefficient $( \pm$ SD) & $P$ \\
\hline Younger age $\mathrm{e}^{*}$ & $-0.31 \pm 0.156$ & .05 \\
\hline $\begin{array}{l}\text { Absence of right coronary } \\
\text { artery disease }\end{array}$ & $-1.32 \pm 0.45$ & .004 \\
\hline $\begin{array}{l}\text { Increasing left ventricular } \\
\text { dysfunctiont }\end{array}$ & $0.12 \pm 0.022$ & $<.0001$ \\
\hline
\end{tabular}

Intercept for model, 1.04; C statistic, 0.69 .

*Exponential transformation of age in years (exp[age/50]).

†Squared transformation of dysfunction ([dysfunction]2). 


\section{Appendix II \\ Details of Data Analysis}

Propensity analysis. The propensity analysis (see Methods) resulted in a logistic equation from which the probability of receiving mitral valve repair rather than replacement could be calculated for each patient. The propensity score was constructed with regard to patient outcome, and the calculation was made regardless of whether the patient actually underwent repair or replacement.

Each patient's propensity score was calculated from the sum of the values for all variables in the model multiplied by their respective logistic coefficients. The patients were then sorted according to the propensity score. Patients with similar propensity scores were well matched for all these factors. Only in the first quintile, however, was there a large, well-matched comparison group of patients. Characteristics of this quintile differed in many important ways from those of the others, particularly with respect to the complexity and consequences of the disease and the prevalence of replacement versus mitral valve repair (Table 5).

Risk factor identification. In the analysis of risk factors, it became clear that the propensity score itself represented a gradient of mortality risk, and within quintiles an increasingly different outcome for repair and replacement. We therefore developed models for the repair and replacement groups separately (Appendix II, Table 1; Appendix II, Table 2). We then combined these analyses, examining every interaction with repair versus replacement. This yielded a model that better fit the data than did the two separate analyses.

Variable selection used two complementary techniques: guided entry of variables into each hazard phase ${ }^{26}$ and bootstrap resampling variable selection (so-called "bagging"). ${ }^{27,28}$ For the latter, the data set was randomly sampled with replacement to generate a data set of the same size. This was repeated 500 times. Each data set was analyzed by automated forward stepwise variable selection. The variables entered into the final model by the directed approach relied on the frequency with which variables appeared in these 500 models. Generally, factors that appeared in $50 \%$ or more of the models were retained. The $P$ value criterion for retention of variables in the final models with this combined variable selection approach was .1, except for the variables repair versus replacement and propensity score, which were forced into the models.

Management of missing data. The data exhibited typical sporadic missing value difficulties. Nearly every patient had missing values for at least one variable. In this setting it is better to retain all patients than to delete individuals with missing values. Therefore all variables were

Appendix II, TABLE 1. Multivariable analyses of death within replacement group $(n=85)$

\begin{tabular}{|c|c|c|}
\hline \multirow[b]{2}{*}{ Incremental risk factors } & \multicolumn{2}{|c|}{ Early hazard phase } \\
\hline & Coefficient $( \pm$ SD) & $\boldsymbol{P}$ \\
\hline \multicolumn{3}{|l|}{ Demographic characteristics } \\
\hline Older age* & $0.79 \pm 0.35$ & .02 \\
\hline \multicolumn{3}{|l|}{ Cardiac comorbidity } \\
\hline $\begin{array}{l}\text { Increasing severity of wall } \\
\text { motion abnormality } \dagger\end{array}$ & $0.09 \pm 0.038$ & .02 \\
\hline \multicolumn{3}{|l|}{ Noncardiac comorbidity } \\
\hline Renal disease & $1.07 \pm 0.39$ & .02 \\
\hline
\end{tabular}

Appendix II, TABLE 2. Multivariable analyses of death within repair group ( $\mathrm{n}=397$ )

\begin{tabular}{|c|c|c|c|c|}
\hline \multirow[b]{3}{*}{ Incremental risk factors } & \multicolumn{4}{|c|}{ Hazard phase } \\
\hline & \multicolumn{2}{|c|}{ Early } & \multicolumn{2}{|c|}{ Late } \\
\hline & Coefficient ( \pm SD) & $\boldsymbol{P}$ & Coefficient $( \pm$ SD) & $\boldsymbol{P}$ \\
\hline \multicolumn{5}{|l|}{ Demographic characteristics } \\
\hline Older age* & $0.61 \pm 0.21$ & .0004 & - & \\
\hline \multicolumn{5}{|l|}{ Clinical status } \\
\hline Higher NYHA functional class $†$ & $0.63 \pm 0.16$ & $<.0001$ & - & \\
\hline \multicolumn{5}{|l|}{ Cardiac comorbidity } \\
\hline Wall motion abnormality site inferiorł & - & & $-0.83 \pm 0.29$ & .004 \\
\hline Wall motion abnormality site lateral & - & & $0.84 \pm 0.29$ & .004 \\
\hline Preoperative atrial fibrillation & - & & $1.07 \pm 0.26$ & $<.0001$ \\
\hline \multicolumn{5}{|l|}{ Valve pathophysiology } \\
\hline Complex jet direction & $1.10 \pm 0.36$ & .002 & - & \\
\hline \multicolumn{5}{|l|}{ Noncardiac comorbidity } \\
\hline Higher preoperative creatinine & $0.24 \pm 0.071$ & .0005 & - & \\
\hline Higher preoperative blood urea nitrogen§ & - & & $0.71 \pm 0.26$ & .007 \\
\hline \multicolumn{5}{|l|}{ Operation } \\
\hline Use of bovine pericardial ring & $0.51 \pm 0.27$ & .05 & - & \\
\hline Absence of ITA grafting & $1.03 \pm 0.38$ & .007 & - & \\
\hline
\end{tabular}

*Exponential transformation (exp[age/50]).

TNYHA functional classes I through $V$, where $V$ is equivalent to IV with emergency surgery.

$\ddagger$ Negative coefficient indicates a beneficial association.

$\S$ Natural logarithmic transformation (In[blood urea nitrogen]). 
scrutinized with respect to the pattern of missing values. If more than $20 \%$ to $25 \%$ of values were missing, the variable was not considered in any analyses. In the remaining cases, the missing informative imputation was not possible. We therefore assumed that the values were missing at random and substituted the mean value for the remainder of the group for the missing values. In addition, we generated indicator variables for each variable with missing values; the value was 0 if the value was present and 1 if it was missing. We incorporated these indicator variables in the propensity score to distribute them appropriately, and we tested for their significance in multivariable modeling. In all cases, patients with missing values behaved with respect to outcome the same $(P>.1)$ as those with values.

Analysis of benefit. In addition to comparing 7-year survivals, we not only simulated the 7-year survival difference between repair and replacement but also constructed complete survival curves for the patients who were predicted to fare better at 7 years with the surgical procedure other than that which they had undergone. For this, the other characteristics of each were entered into the multivariable equation (Table 6) to generate a patient-specific survival curve and to calculate the cumulative hazard at the actual time of follow-up. The curves were averaged and compared with Kaplan-Meier estimates of actual outcome. ${ }^{29}$ With the sum of the cumulative hazard values, the predicted number of deaths was compared with the actual number.

\section{Appendix III}

\section{Variables Considered in Risk Analyses}

Demographic characteristics

- Age (years)

- Height (centimeters)

- Weight (kilograms)

- Body mass index (kilograms per square meter)

- Body surface area (square meters)

- Gender Symptoms and clinical status

- Emergency surgery

- NYHA functional class (I through IV, and also augmented from class IV to new class V for emergency operations)

- Preoperative use of intra-aortic balloon pump Left ventricular function

- Preoperative acute versus remote myocardial infarction (acute myocardial infarction occurring within 14 days of surgery)

- Timing of most recent myocardial infarction in relation to surgery (continuous variable)

- Severity of left ventricular dysfunction (1, none; 2 , mild; 3 , moderate; 4 , severe)

- Site of infarction or wall motion abnormality (septal, inferior, anterior, lateral, posterior)

- Jet direction (central, anterior, posterior, complex) Pathophysiology of valve disease

- Degree of mitral regurgitation (1, mild; 2, moderate; 3, moderate to severe; 4 , severe)

- Mitral stenosis

- Left ventricular thromboembolism
- Mitral valve pathology: functional mitral regurgitation, elongated or infarcted papillary muscle, rupture of papillary muscle Cardiac comorbidity

- Family history of coronary artery disease

- Preoperative atrial fibrillation

- Left ventricular dysfunction ( 0 , normal; 1 , mild; 2 , moderate; 3 , severe)

- Coronary artery disease (maximum stenosis in left main trunk, left anterior descending, circumflex, and right coronary trunk systems)

- Extent of coronary system disease (1, one-system disease; 2, two-system disease; 3, three-system disease)

Noncardiac comorbidity

- Blood urea nitrogen (milligrams per deciliter)

- Creatinine (milligrams per deciliter)

- Renal disease

- Cholesterol

- Bilirubin

- Treated diabetes

- Smoking

- Hypertension

- Chronic obstructive pulmonary disease

- Peripheral vascular disease Operation

- Mitral valve replacement versus repair

- Mitral valve repair: annuloplasty (with or without ring, Carpentier-Edwards, Cosgrove, bovine pericardial annuloplasty), annular plication, annular decalcification, leaflet resection (quadrangular or not) or suture, chordal resection, chordal shortening or transfer, papillary muscle shortening

- Surgeon (separate indicator variable for each of the 6 high-volume surgeons and an indicator for low-volume surgeon, see Methods)

- Date of operation (number of years since January 1, 1985) Concomitant procedures

- Coronary artery bypass grafting

- ITA grafting

- Single versus bilateral ITA grafting

- Tricuspid valve replacement or repair

\section{Appendix IV}

\section{Repair Versus Replacement: Lines of Evidence}

The answer to the question, "Is repair better than replacement?" is not a simple yes or no but "depends." The lines of evidence are as follows.

1. Even though mitral valve replacement was rare for much of the spectrum of the disease and patient condition, the survival increased progressively after repair as patient condition became better and the lesion became simpler, whereas survival after replacement remained about the same (Figure 3).

2. The risk factors for the replacement group were nonspecific (Appendix II, Table 2) compared with those for the repair group 
(Appendix II, Table 1), which allowed larger gradients of risk to be identified for the group. A limitation of this line of evidence is the relatively small number of valve replacements.

3. An initial and identical-factor multivariable analysis was generated for quintiles I and II and then extended to include sequentially quintiles III, IV, and V (not shown). The $P$ value for replacement as a risk factor in the early hazard phase steadily decreased from .3 (quintiles I and II) to .1, .08, and .02.

\section{Appendix V}

Who Benefits?

The multiple linear regression for the difference in 7-year survival is presented in Appendix V, Table 1. When the equation is solved for a given patient's characteristics, a positive value predicts a benefit for replacement and a negative value predicts a benefit for repair strictly on the basis of point estimates.

Patients undergoing mitral valve replacement who were predicted to fare better with repair are shown in Appendix V, Figure 1 (see Appendix II for details of constructing these patient-specific survival curves). Their time-related pattern of survival was better than that observed, and the number of predicted deaths $(\mathrm{n}=18)$ was lower than the actual number $(\mathrm{n}=27, P=.01)$. In contrast, those patients who actually underwent repair but were predicted to fare better at 7 years with replacement merely demonstrated a different survival pattern, with more early deaths and fewer late ones (Appendix V, Figure 2), resulting in no saving of lives $(\mathrm{n}=61.5$ predicted vs $\mathrm{n}=64$ observed, $P=.98$ ).

Appendix V, TABLE 1. Factors influencing magnitude of survival benefit associated with mitral valve repair versus replacement (multiple linear regression)*

\begin{tabular}{|c|c|c|}
\hline Variable & Coefficient ( \pm SD) & $\boldsymbol{P}$ \\
\hline \multicolumn{3}{|l|}{ Demographic characteristics } \\
\hline Age & $0.51 \pm 0.040$ & $<.0001$ \\
\hline \multicolumn{3}{|l|}{ Clinical status } \\
\hline Emergency surgery & $7.2 \pm 1.44$ & $<.0001$ \\
\hline \multicolumn{3}{|l|}{ Cardiac comorbidity } \\
\hline Left ventricular dysfunctiont & $0.78 \pm 0.078$ & $<.0001$ \\
\hline Lateral wall motion abnormality & $-17.2 \pm 0.82$ & $<.0001$ \\
\hline Inferior wall motion abnormality & $6.3 \pm 0.89$ & $<.0001$ \\
\hline Atrial fibrillation & $-10.7 \pm 0.80$ & $<.0001$ \\
\hline \multicolumn{3}{|l|}{ Valve pathophysiology } \\
\hline Complex regurgitant jet & $-13.1 \pm 1.09$ & $<.0001$ \\
\hline \multicolumn{3}{|l|}{ Noncardiac comorbidity } \\
\hline Blood urea nitrogen $\ddagger$ & $-3.2 \pm 1.17$ & $<.0001$ \\
\hline \multicolumn{3}{|l|}{ Operative variables } \\
\hline ITA graft & $7.9 \pm 0.78$ & $<.0001$ \\
\hline
\end{tabular}

Intercept for model, $-17.8 ; r^{2}, 0.68$.

*A positive value for the solution of the linear regression equation is indicative of a repair benefit, whereas a negative value is indicative of a replacement benefit.

TSquare transformation of dysfunction ([dysfunction] ${ }^{2}$ ).

$\ddagger$ Natural logarithmic transformation of blood urea nitrogen in milligrams per deciliter (In[blood urea nitrogen]).

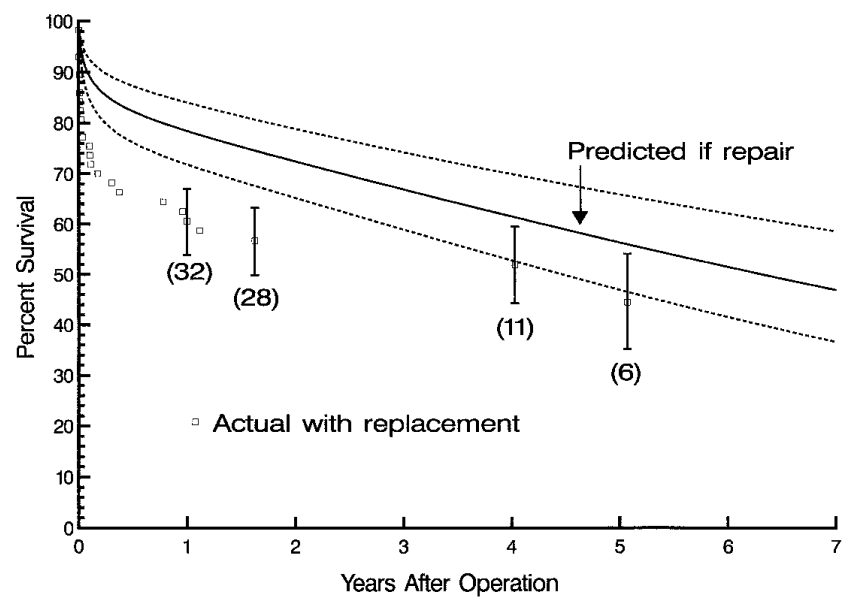

Appendix V, Figure 1. Simulated mitral valve repair (solid line) for patients actually undergoing replacement (squares depict KaplanMeier estimates and confidence limits, as in Figure 2). Simulated curve was obtained from patient-specific estimates, as described in Appendices II and V.

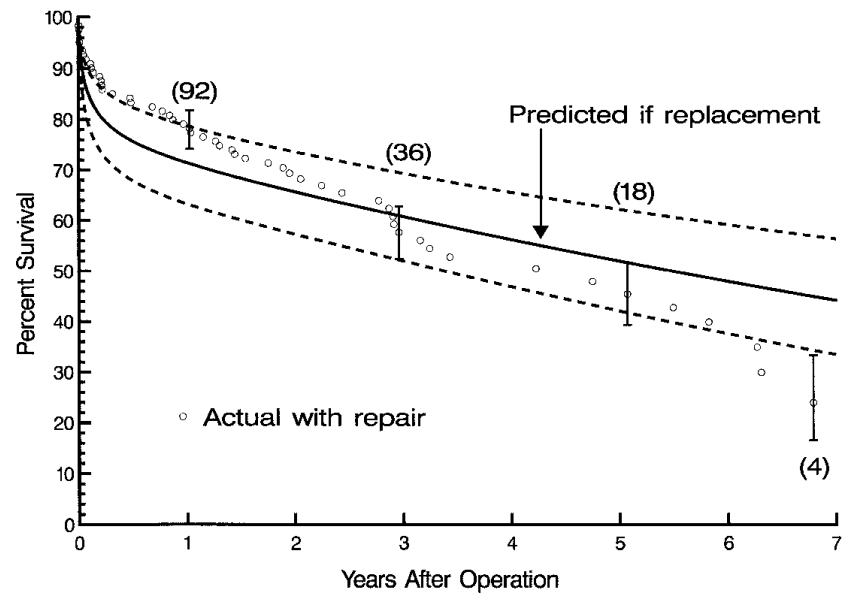

Appendix V, Figure 2. Simulated mitral valve replacement (solid line) for patients actually undergoing repair (circles depict Kaplan-Meier estimates and confidence limits, as in Figure 2). Simulated curve was obtained from patient-specific estimates, as described in Appendices II and V. 